\title{
ISOKINETIC EVALUATION AFTER TWO-STAGE BICRUCIATE RECONSTRUCTION
}

\author{
Igor Gigliotakaes ${ }^{1}$, Mauro Mituso Inada ${ }^{1}$, João Batista de Miranda ${ }^{2}$, Sérgio Augusto Cunha ${ }^{3}$, Sérgio Rocha Piedade ${ }^{1}$
}

\section{ABSTRACT}

Objective: To assess the functional balance of the knee after bicruciate reconstruction and its correlation with clinical score. Methods: 14 patients (11 men and three women), mean age $29.9 \pm 7.65$ years, mean BMl $26.2 \pm 2.51 \mathrm{~kg} / \mathrm{m}^{2}$ underwent surgical reconstruction of the Posterior Cruciate Ligament $(\mathrm{PCL})$ and Anterior Cruciate Ligament (ACL) in two stages, with a mean interval of 3 months between procedures. With a mean follow-up period of 27.33 months, the isokinetic knee analysis was performed at $60 \%$ s and $180 \%$ s and the Lysholm and Tegner scores were applied. Results: The Lysholm score was $86.8 \pm 11.1$ points and the Tegner score showed a deficit of $30 \%$ compared to pre-injury level. In isokinetic evaluation, the deficit of the operated quadriceps average torque was
$17.05 \%$ at $60 \%$ and $12.16 \%$ at $180 \%$ s, while the average flexor torque deficit was $3.43 \%$ at $60 \%$ s and $5.82 \%$ at $180 \%$ s. Although it was observed torque deficit between members, there were no statistical differences regarding the functional balance between hamstrings and quadriceps. Conclusion: Although the results of isokinetic evaluation has shown a functional balance of the knee (flexor-extensor), which may have contributed to the good subjective Lysholm score in the bicruciate two-stage reconstruction, two-stage reconstruction did not restore the pre-injury functional level. Level of Evidence IV, Case Series.

Keywords: Posterior cruciate ligament. Anterior cruciate ligament. Knee. Biomechanics.

Citation: Takaes IG, Inada MM, Miranda JB, Cunha SA, Piedade SR. Isokinetic evaluation after two-stage bicruciate reconstruction. Acta Ortop Bras. [online]. 2014;22(1):21-4. Available from URL: http://www.scielo.br/aob.

\section{INTRODUCTION}

Concomitant lesions of cruciate ligaments alter the stability of the knee arthrokinematics and therefore affect the patients quality of life. In most cases, surgical treatment is the adopted treatment, due to the nature of this highly disabling injury. Another aspect to be considered is that the literature has not yet established a consensus on the best surgical approach. Therefore, non-uniformity causes variable surgical approach conducts (one or two phases), the tendon graft option, the fastening system option, among others.

Although clinical scores constitute an important source of information to evaluate the postoperative results, they provide no objective data of muscular knee balance..$^{1-3}$ Within this context, the isokinetic dynamometer presents itself as an interesting tool since, while recording muscle function data enables more detailed analysis of the functional balance of the knee.

In this research the postoperative results of the reconstruction of bicruciate chronic knee injury performed in two surgical pha- ses was analyzed by Lysholm and Tegner clinical scores and compared to data obtained by isokinetic dynamometer.

\section{MATERIALS AND METHODS}

From 2002 to 201031 patients underwent ligament reconstruction of the bicruciate knee complex.

Seventeen patients according to the following criteria were excluded): bicruciate bilateral lesion (one patient), prior tibial osteotomy (two patients), femur fractures and/or ipsilateral tibia (eight patients), lack of follow up (two patients), and patients who did not attend the isokinetic evaluation (four patients).

\section{Patients and mechanism of injury}

Fourteen patients were evaluated, three male and eleven female subjects, mean age $29.9 \pm 7.65$ years and mean BMl $26.2 \pm$ $2.51 \mathrm{~kg} / \mathrm{m} 2$. (Table 1) As shown in Table 1, in $57.1 \%$ of cases the mechanism of injury were associated to automobile, motorcycle and bicycle accidents, while $42.9 \%$ suffered sprains related to daily and sports activities. (Table 2 ) The time of injury ranged

All the authors declare that there is no potential conflict of interest referring to this article.

\footnotetext{
1. Sports and Exercise Medicine Group, Faculdade de Ciências Médicas, Unicamp, Campinas, SP, Brazil.

2. Department of Orthopedics and Traumatology, Faculdade de Ciências Médicas, Unicamp, Campinas, SP, Brazil.

3. Faculdade de Educação Física, Unicamp, Campinas, SP, Brazil.

Research performed at Sports and Exercise Medicine Group, Faculdade de Ciências Médicas, Unicamp, Campinas, SP, Brazil.

Correspondence: Sérgio Rocha Piedade, Rua Tessália Vieira de Camargo, 126, Cidade Universitária "Zeferino Vaz", Distrito de Barão Geraldo. Campinas, SP, Brazil. CEP 13086-887.
} piedade@unicamp.br 
from 1 to 46 months with a mean of $10.21 \pm 13.07$ months. The research project was approved by the Ethics and Research Committee of this institution, under the protocol no 963/ 2010.

Table 1. Distribution of the 14 studied patients according to age, gender, BMl and injured knee.

\begin{tabular}{c|c|c|c|c}
\hline Patient & Gender & Age & BMI & Injured Knee \\
\hline 1 & $\mathrm{~F}$ & 16 & 19.9 & $\mathrm{R}$ \\
\hline 2 & $\mathrm{~F}$ & 18 & 28 & $\mathrm{R}$ \\
\hline 3 & $\mathrm{M}$ & 22 & 27.9 & $\mathrm{~L}$ \\
\hline 4 & $\mathrm{M}$ & 23 & 28 & $\mathrm{R}$ \\
\hline 5 & $\mathrm{M}$ & 27 & 26.4 & $\mathrm{R}$ \\
\hline 6 & $\mathrm{M}$ & 21 & 25.2 & $\mathrm{R}$ \\
\hline 7 & $\mathrm{M}$ & 27 & 25 & $\mathrm{R}$ \\
\hline 8 & $\mathrm{M}$ & 26 & 26.2 & $\mathrm{~L}$ \\
\hline 9 & $\mathrm{M}$ & 26 & 27.7 & $\mathrm{R}$ \\
\hline 10 & $\mathrm{M}$ & 29 & 26.9 & $\mathrm{R}$ \\
\hline 11 & $\mathrm{M}$ & 26 & 24.1 & $\mathrm{~L}$ \\
\hline 12 & $\mathrm{M}$ & 30 & 24 & $\mathrm{~L}$ \\
\hline 13 & $\mathrm{M}$ & 35 & 26.9 & $\mathrm{R}$ \\
\hline 14 & $\mathrm{~F}$ & 44 & 30.5 & $\mathrm{R}$ \\
\hline
\end{tabular}

Table 2. Characterization of the injury mechanism and associated injuries.

\begin{tabular}{|c|c|c|c|c|c|}
\hline \multirow[b]{2}{*}{ Patient } & \multirow[b]{2}{*}{$\begin{array}{l}\text { Lesion } \\
\text { mechanism }\end{array}$} & \multicolumn{4}{|c|}{ Associated Lesions } \\
\hline & & $\begin{array}{l}\text { Peripheral } \\
\text { ligament }\end{array}$ & Meniscal & Chondral & Fractures \\
\hline 1 & Bicycle & $\mathrm{MCL}$ & $-\cdots$ & -..- & -..- \\
\hline 2 & Motorcycle & MCL/PT & Yes & -.-- & -.-- \\
\hline 3 & Motorcycle & PLC & Yes & Yes & $-\cdots-$ \\
\hline 4 & Bicycle & -.-- & Yes & Yes & -... \\
\hline 5 & Motorcycle & PT & $-\ldots$ & ---- & --- \\
\hline 6 & Sports & Yes & -... & -..- & -... \\
\hline 7 & Motorcycle & PLC & --- & Yes & --- \\
\hline 8 & Sports & $\mathrm{MCL}$ & Yes & $-\cdots$ & $-\cdots-$ \\
\hline 9 & Automobile & PLC & $-\cdots-$ & $-\cdots$ & Clavicle fracture $+\mathrm{C} 2$ \\
\hline 10 & Fall & -..- & Yes & Yes & -.-- \\
\hline 11 & Motorcycle & --- & --- & --- & --- \\
\hline 12 & Motorcycle & --- & --- & Yes & Forearm fracture \\
\hline 13 & Sports & --- & Yes & Yes & --- \\
\hline 14 & Fall & -.-- & -.-- & --.- & $-\ldots$ \\
\hline
\end{tabular}

MCL: Medial collateral ligament; LCL: Lateral collateral ligament; PT: Patellar Tendon; PLC: posterolateral corner.

\section{Surgical approach}

The first surgical phase involved the reconstruction of the PCL via open approach (inlay technique), with grafted of the central third of the patellar tendon using fixation with interference screw in the femoral tunnel and cortical screw with washer in the tibia. The knee was held in extension with malleolar-inguinal splint for six weeks.

After a minimum interval of three months, the patient underwent anatomic $\mathrm{ACL}$ reconstruction by arthroscopy using quadruple graft of flexors tendons and femoral and tibial fixation with interference screws. (Figure 1) Two patients underwent reconstruction of the medial collateral with semitendinosus gracilis and contralateral graft, and approximately $42.8 \%$ of patients received partial meniscectomy since they had chondral lesion (grade $\leq 2$ ). Patients underwent an individualized rehabilitation program after surgeries.

\section{Postoperative evaluation}

With a mean postoperative follow-up of 27.33 months (9 to 92), patients underwent clinical evaluation (physical examination),
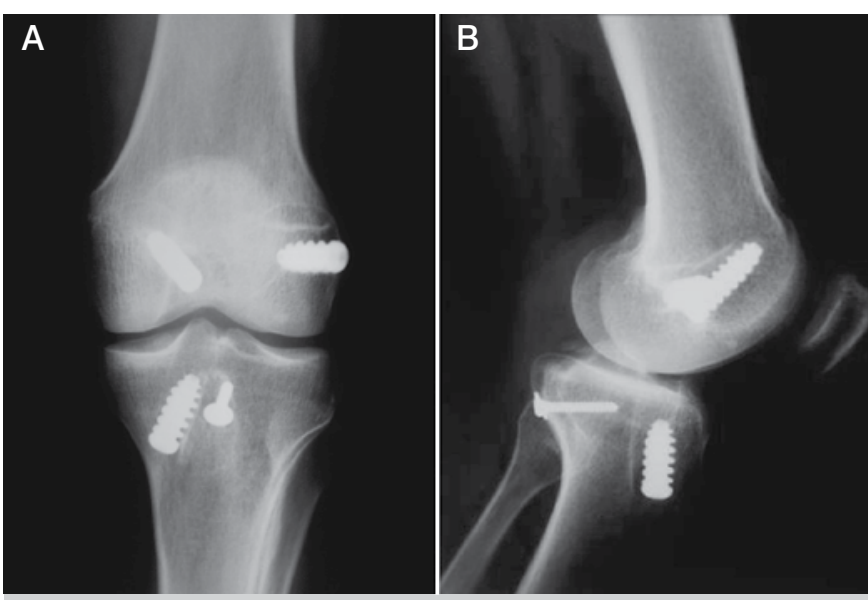

Figure 1. Radiologic control of the reconstruction of the left knee bicruciate at the anteroposterior $(A)$ and profile (B) views.

radiological evaluation and were submitted to clinical Lysholm score (subjective parameter) and Tegner score (function level pre and postoperatively). Thus, the percentage variation between the final Tegner score compared with its preoperative status (Tegener deficit) was determined.

To perform the isokinetic assessment, a Biodex 3 dynamometer (Biodex Medical Systems, Inc.) was used. Initially, the patient performed a warming up session in an ergometric bicycle for five minutes. Then, he was accommodated in a dynamometric chair stabilized by belts in the chest, hip and thigh of each member tested. The mechanical axis of the dynamometer was set in the center of the lateral femoral condyle and the lever arm was fixed to the distal end of the tibia. (Figure 2)

The test was performed at three angular speeds, in the concentric/concentric mode, being: $60 \%$ s (analysis of the maximum torque of the extensor/flexor muscle of the knee) and $180 \% \mathrm{~s}$ (speed commonly used during sports gestures), according to procedure described in studies prévios. ${ }^{4-6}$

A series of five repetitions with voluntary contraction for every speed $(60 \%$ and $180 \%$ s) was carried out. There was a 90

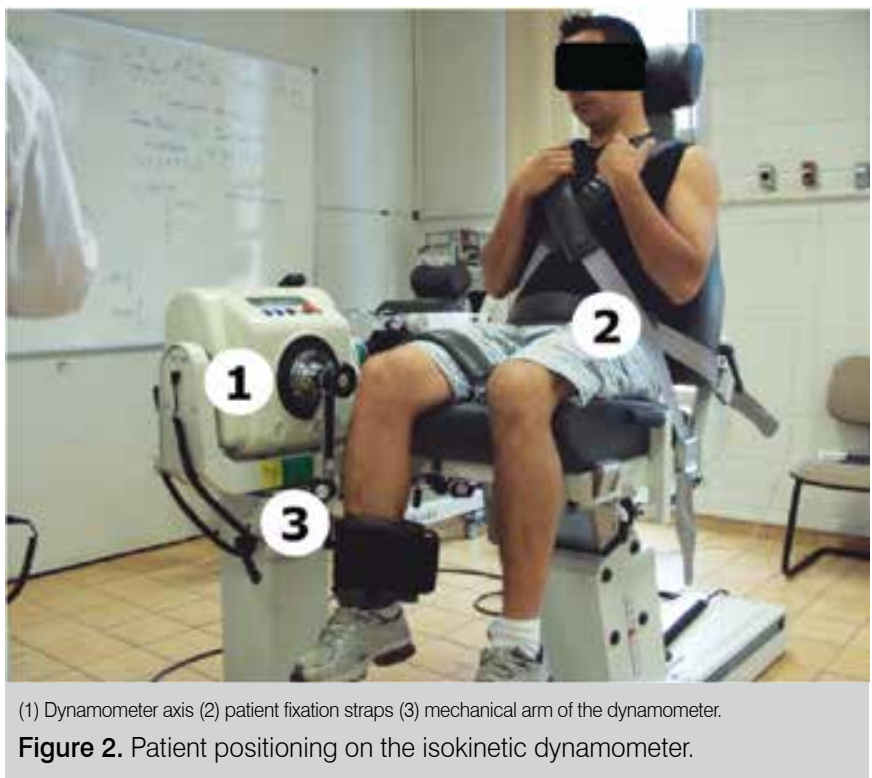


seconds rest period between between each series. The deficit of extensor and flexor torque was calculated comparing the torque peak between the operated member LIMB (TPOL) and control LIMB (TPCL), according to described below:

$$
\% \text { Déficit }=\left[\frac{(\mathrm{TPOL}-\mathrm{TPCL})}{\mathrm{TPCL}}\right] \times 100
$$

The muscular balance between the flexors and extensors muscles of the knee was calculated based on the ratio between the peak of agonist/antagonist torque (hamstring/quadriceps $=H / Q$ ).

\section{Statistical analysis}

A statistical analysis was carried out through the software SAS system for Windows, version 9.1.3. In order to compare the numerical variables between two groups the test of MannWhitney was used, due to the absence of normal distribution of the variables. With the aim of analyzing the relationship among the numerical variables, Spearman's correlation coefficient was used. In order to compare between Tegner score pre and postoperatively, the Wilcoxon test for related samples was used. The isokinetic data were compared among the sides and the speeds, and the analysis of variance for Repeated Measures (ANOVA) was used, followed by the test of profile by contrasts in order to analyze the parameters among the sides and among the speeds. The variables were turned into positions (ranks) for analyses, due to the absence of normal distribution. The level of significance adopted for the statistical tests was of $5 \%$, i.e. $P<0.05$.

\section{RESULTS}

The posterior drawer test was reported as negative in three patients $(21.4 \%)$, while 11 patients $(78.6 \%)$ had residual posterior drawer $0.5 \mathrm{~cm}(+/+++)$.

Data referring to Lysholm score and Tegner questionnaire preinjury and post-surgery are shown in Table 3.

Patients reported a mean value of pre-injury Tegner score 5

Table 3. Mean values and standard deviation of the Lysholm questionnaire, pre-injury and postoperative.

\begin{tabular}{|c|c|c|c|c|c|}
\hline \multirow{2}{*}{ Patients } & \multirow{2}{*}{ Lysholm } & \multirow{2}{*}{ Assessment } & \multicolumn{3}{|c|}{ Tegner } \\
\hline & & & Pre-lesion & Postoperative & Deficit (\%) \\
\hline 1 & 93 & Good & 6 & 3 & 50.00 \\
\hline 2 & 65 & Poor & 4 & 3 & 25.00 \\
\hline 3 & 92 & Good & 9 & 7 & 22.22 \\
\hline 4 & 95 & Good & 5 & 4 & 20.00 \\
\hline 5 & 97 & Excellent & 5 & 4 & 20.00 \\
\hline 6 & 98 & Excellent & 6 & 4 & 33.33 \\
\hline 7 & 89 & Good & 3 & 2 & 33.33 \\
\hline 8 & 82 & regular & 3 & 2 & 33.33 \\
\hline 9 & 68 & regular & 3 & 2 & 33.33 \\
\hline 10 & 96 & Excellent & 7 & 4 & 42.86 \\
\hline 11 & 86 & Good & 3 & 2 & 33.33 \\
\hline 12 & 95 & Excellent & 9 & 7 & 22.22 \\
\hline 13 & 72 & Good & 7 & 5 & 28.57 \\
\hline 14 & 87 & Good & 3 & 2 & 33.33 \\
\hline $\begin{array}{c}\text { Mean } \pm S t \\
\text { Dev }\end{array}$ & $86.79 \pm 11.06$ & $\begin{array}{c}E(4)-G(7) \\
-R(2)-P(1)\end{array}$ & $5.21 \pm 2.19$ & $3.64 \pm 1.74$ & $30.78 \pm 8.64$ \\
\hline
\end{tabular}

and postoperative Tegner score 4 . Thus, it is emphasized that Tegner's deficit was $30 \%(p<0.001)$.

\section{Isokinetic analysis}

It is reported below the peak flexor and extensor torque and their mean values and standard deviations, at speeds of $60 \%$ and $180 \%$ s. (Table 4)

During this analysis, we see that the operated limb and the control presented an increasing agonist/antagonist relationship at speeds of $60 \%(0.59 \pm 0.12$ and $0.51 \pm 0.10$, respectively $)$ and $180 \%$ s $(0.65 \pm 0.10$ and $0.60 \pm 0.15$, respectively), but no statistical differences among limbs.

Table 4. Mean values of extensor and flexor torque at the angular speeds $60 \%$ s, $180 \%$ s and $300 \%$ s.

\begin{tabular}{c|c|c|c|c}
\hline \multicolumn{5}{c}{ Extensor torque (Mean and St. Dev.) } \\
\hline Speed & Operated & Control & P value & Deficit \\
\hline $60 \% / s$ & $167,21 \pm 44,16$ & $209,66 \pm 50,22$ & $\mathrm{p}=0,02$ & $17,06 \pm 27,89 \%$ \\
\hline $180 \% / \mathrm{s}$ & $122,65 \pm 33,89$ & $145,76 \pm 38,98$ & $\mathrm{p}=0,02$ & $12,16 \pm 30,05 \%$ \\
\hline \multicolumn{5}{c}{ Flexor torque (Mean and St. Dev.) } \\
\hline Speed & Operated & Control & P value & Deficit \\
\hline $60 \% / \mathrm{s}$ & $98,11 \pm 29,24$ & $106,65 \pm 29,48$ & $\mathrm{~ns}$ & $3,43 \pm 28,47$ \\
\hline $180 \% / \mathrm{s}$ & $79,12 \pm 23,60$ & $85,66 \pm 24,52$ & $\mathrm{~ns}$ & $5,82 \pm 19,46$ \\
\hline
\end{tabular}

\section{DISCUSSION}

The most important finding of this study was to identify that although isokinetic dynamometry has shown differences in the values of flexor and extensor torque between the operated knee and control, the relationship agonist/antagonist was similar in both knees, which contributed to a mean score of Lysholm rated as good. Furthermore, the postoperative evaluation fell by $30 \%$ in relation of the pre-injury functional activity.

Wascher et al. ${ }^{3}$ studied 13 patients that underwent simultaneous reconstruction of the bicruciate complex and recorded 88 points on average on Lysholm questionnaire, while Schofer et al. ${ }^{7}$ reported an average Lysholm score of 74 points in the series of nine patients with bicruciate lesions. In another study, Zhao et al. ${ }^{8}$ performed the reconstruction of bicruciate complex in 21 cases and obtained 91.9 points.

Hirschman et al..$^{9,10}$ presented two series with results classified as good (91.8 points) and regular (83 points), evaluating 68 and 26 patients, respectively. Fanelli et al. ${ }^{11}$ obtained a mean score of 91.2 points after bicruciate reconstruction performed in a surgical procedure in 35 patients with postoperative follow-up ranging from 24 to 120 months.

In this case series, the surgical approach performed at two stages gave a mean value of $86.79 \pm 11.06$ points, being classified as good in Lysholm score, at $29.9 \pm 7.65$ months postoperatively. Of these patients, four (28.6\%) were classified as excellent, seven (50\%) as good, two (14.3\%) as regular and one $(7.1 \%)$ as poor. Considering the Tegner score, the literature shows reduced physical activity ranging from $11.5 \%$ to $22.3 \%$ after reconstruction of the bicruciate knee. Mariani et al. ${ }^{12}$ recorded an average deficit of $25 \%$ compared to pre-injury status (6.9 and 5.5 , respectively), on the $36^{\text {th }}$ postoperative month, while Tsubarkis et al. ${ }^{13}$ reported a $12.5 \%$ deficit (4.2 points) compared to pre-injury status (4.8 points), in series of 25 patients, at mean follow-up of 51.3 months. 
In the present study, the average deficit recorded was 30.8\% $(5.21 \pm 2.19$ and $3.64 \pm 1.74$ in the pre-injury and post -surgery assessment, respectively), i.e., a higher percentage than reported in the literature. Thus, unlike previous studies that evaluated acute and chronic cases, in this study the chronicity of the lesion (27.36 \pm 24.4 months) may have contributed to these results. Considering the isokinetic analysis, Lindahl et al. ${ }^{14}$ obtained a mean peak extensor torque of $160.1 \mathrm{~N} . \mathrm{m}$ and $104.7 \mathrm{~N} . \mathrm{m}$ at speeds of $60 \%$ and $180 \%$, respectively, at 56 months postoperatively ( $n=47$ patients) while in this series $(n=14$ patients), the values of peak torque in the operated limb (Table 4) were slightly higher, $167.21 \mathrm{M} . \mathrm{m}$ and $122.65 \mathrm{~N} . \mathrm{m}$, at the respective velocities $(60 \%$ s and $180 \%$ s).

The bicruciate reconstruction is invariably accompanied by greater extensor deficit when comparing with the isolated ligament reconstructions LCP or LCA. ${ }^{7,8}$ Considering the acquisition speed of $180 \%$, Wascher et al. ${ }^{3}$ recorded an average extensor deficit of $11 \% 38$ months after the bicruciate reconstruction, whereas other authors have reported deficits ranging between $8 \%$ and $15.3 \% .{ }^{1,15}$ Moreover, Schofer et al. ${ }^{7}$ observed higher values of extensor deficit $(41 \%)$ at $60 \%$ in nine patients that underwent the same surgical procedure at 37 months of postoperative follow-up, while Lo et al..$^{16}$ described a $10 \%$ deficit $(n=11$ patients) at 55 months follow-up.

In this study, the operated knee showed a significant deficit in the medium expansion velocities of $60 \%$ s (17.1\%) and $180 \%$ s (12.2\%) compared to the control knee ( $p=0.02$ in both cases). (Table 4) Assessing the postoperative flexor torque deficit at the angular speed of $180 \%$ s, the literature shows a deficit ranging from $7.5 \%$ to $13 \%$. $3,15,16$ In the present study, the average value of flexor torque was $5.82 \%$ at $180 \%$ and $3.43 \%$ at $60 \%$ $(p<0.01)$. (Table 4$)$ In addition, in this study the mean values of the agonist/antagonist relationship $(\mathrm{H} / \mathrm{Q})$ were 0.59 at $60^{\circ}$ and 0.65 at $180 \%$ s $(p<0.001)$, (Table 5) values lying in the same range reported for $\mathrm{ACL}$ reconstruction, i.e., $\mathrm{H} / \mathrm{Q}$ ranging between 0.5 and 0.6 at the angular speed of $60 \%$ and 0.7 at $180 \% \mathrm{~s}^{17-19}$ The limitations of this analysis lie in the fact that it is a retrospective, nonrandomized study that examines a series made exclusively by chronic cases. However, the importance of this study is the analysis of case series of complex ligamentous injuries, operated by a single surgeon with uniform technique, mean postoperative follow-up over 24 months and the comparison of data obtained from clinical scores (Lysholm and Tegner) with isokinetic dynamometry.

\section{CONCLUSION}

Although isokinetic dynamometry has shown differences in the values of flexor and extensor torque between the operated knee and control, the agonist/antagonist relationship was similar in both knees, which contributed to the average Lysholm score to be rated as good. However, bicruciate reconstruction in two surgical phases did not restore the level of pre-injury functional activity.

\section{REFERENCES}

1. Jenkins PJ, Clifton R, Gillespie GN, Will EM, Keating JF. Strength and function recovery after multiple-ligament reconstruction of the Knee. Injury. 2011;42 (12):1426-9.

2. Piedade SR, Munhoz RR, Cavenaghi G, Miranda JB, Mischan MM. Reconstrução do LCP joelho: técnica de fixação no leito tibial ("inlay"). Avaliação objetiva e subjetiva de 30 casos. Acta Ortop Bras. 2006;14(2):92-6.

3. Wascher DC, Becker JR, Dexter JG, Blevins FT. Reconstruction of the anterior and posterior cruciate ligaments after knee dislocation. Am J Sports Med. 1999;27(2):189-96.

4. Pua Y, Bryant AL, Steele JR, Newton RU, Wrigley TV. Isokinetic dinamometry in anterior cruciate ligament injury and reconstruction. Ann Acad Med Singapore. 2008;37:330-40.

5. Kim S, Park I. Arthroscopic reconstruction of the posterior cruciate ligament using tibial-inlay and double-blundle technique. Arthroscopy. 2005;21(10):1271 e1-1271.e6.

6. Mattacola CG, Perrin DH, Gansneder BM, Gieck JH, Saliba EN, McCue FC 3rd. Strength, functional outcome, and postural stability after anterior cruciate ligament reconstruction. J Athl Train. 2002;37(3):262-8.

7. Schofer MD, Peterlein CD, Fuchs-Winkelmann S, Kortmann HR. [Arthroscopically-assisted combined anterior and posterior cruciate ligament reconstruction]. Unfallchirurg. 2008;111(9):703-10.

8. Zhao J, He Y, Wang J. Simultaneous arthroscopic reconstruction of the anterior and posterior cruciate ligaments with autogenous hamstring tendons. Arthroscopy. 2006;22(5):497-504.

9. Hirschmann MT, Zimmermann N, Rychen T, Candrian C, Hudetz D, Lorez LG, et al. Clinical and radiological outcomes after management of traumatic knee dislocation by open single stage complete reconstruction/repair. BMC Musculoskelet Disord. 2010;11:102.
10. Hirschmann MT, Iranpour F, Müller W, Friederich NF. Surgical treatment of complex bicruciate knee ligament injuries in elite athletes: what long-term outcome can we expect? Am J Sports Med. 2010;38(6):1103-9.

11. Fanelli GC, Orcutt DR, Edson CJ. The multiple-ligament injured knee:evaluation, treatment, and results. Arthroscopy. 2005;21(4):471-86

12. Mariani PP, Margheritini F, Camillieri G. One-stage arthroscopically assisted anterior and posterior cruciate ligament reconstruction. Arthroscopy. 2001;17(7):700-7.

13. Tzurbakis M, Diamantopoulos A, Xenakis T, Georgoulis A. Surgical treatment of multiple knee ligament injuries in 44 patients: 2-8 years follow-up results. Knee Surg Sports Traumatol Arthrosc. 2006;14(8):739-49.

14. Lindahl J, Hietaranta H, Koskinem S, Hirvesalo, E. Knee dislocations: outcome of surgical treatment. Suomen Ortop J Traumatol. 2008;31:31-5.

15. Goudie EB, Will EM, Keating JF. Functional outcome following PCL and complex knee ligament reconstruction. Knee. 2010;17(3):230-4.

16. Lo YP, Hsu KY, Chen LH, Wang CJ, Yeh WL, Chan YS, et al. Simultaneous arthroscopic reconstruction of the anterior and posterior cruciate ligament using hamstring and quadriceps tendon autografts. J Trauma. 2009;66(3):780-8.

17. Dvir Z. Isocinética: avaliações musculares, interpretações e aplicações clínicas. São Paulo: Barueri, SP: Manole; 2002.

18. Fernandes TL, Protta TR, Fregni F, Neto RB, Pedrinelli A, Camanho GL, et al. Isokinetic muscle strength and knee function associated with double femoral pin fixation and fixation with interference screw in anterior cruciate ligament reconstruction. Knee Surg Sports Traumatol Arthrosc. 2012;20(2):275-80.

19. Krishnan C, Williams GN. Variability in antagonist muscle activity and peak torque during isometric knee strength testing. lowa Orthop J. 2009;29:149-58. 